\title{
Exploring the association between ingestion of foods with higher potential salicylate content and symptom exacerbation in chronic rhinosinusitis. Data from the National Chronic Rhinosinusitis Epidemiology Study*
} \author{
Shahram Anari11, Robert Almeyda ${ }^{12}$, Andrew Wilson' \\ ${ }^{1}$ Norwich Medical School, University of East Anglia, Norfolk NR4 7TJ, United Kingdom \\ 2 James Paget University Hospital NHS Foundation Trust, Gorleston, United Kingdom \\ ${ }^{3}$ Royal Sussex County Hospital, Surrey, United Kingdom \\ ${ }^{4}$ Guys \& St Thomas'Hospital, London, United Kingdom \\ ${ }^{5}$ Freeman Hospital, Newcastle, United Kingdom \\ ${ }^{6}$ Sheffield University Teaching Hospitals, Sheffield, United Kingdom \\ Royal Surrey County Hospital, Guildford, United Kingdom \\ ${ }^{8}$ Darlington Memorial Hospital, United Kingdom \\ ${ }^{9}$ Wrightington, Wigan \& Leigh NHS Foundation Trust, United Kingdom \\ ${ }^{10}$ Southern General Hospital, Glasgow, United Kingdom \\ "Birmingham Heartlands Hospital, Birmingham, United Kingdom \\ ${ }^{12}$ Royal Berkshire Hospital, Reading, United Kingdom
}

Carl M. Philpott ${ }^{1,2}$, Rupert Smith 1,2, Cameron R. Davies-Husband³, Sally

Rhinology 57: 4, 303 - 312, 2019 Erskine', Allan Clark1, Ailsa Welch', Claire Hopkins ${ }^{4}$, Sean Carrie ${ }^{5}$, Jaydip Ray 6 , https://doi.org/10.4193/Rhin19.027 Vishnu Sunkaraneni ${ }^{7}$, Naveed Kara ${ }^{8}$, Nirmal Kumar ${ }^{9}$, Alasdair Robertson ${ }^{10}$, Accepted: April 5, 2019

\section{Abstract}

Introduction: Pharmacological salicylates are known to trigger respiratory exacerbations in patients with Non-Steroidal Exacerbated Respiratory Disease (N-ERD), a specific phenotype of Chronic Rhinosinusitis (CRS) and asthma. The impact of dietary sources of salicylates across subgroups of CRS is not well understood. The hypothesis is that in patients with nasal polyps present, there is likely to be a higher incidence of symptom exacerbation due to dietary salicylates regardless of any known response to pharmacological salicylate.

Methods: The Chronic Rhinosinusitis Epidemiology Study (CRES) was a questionnaire-based case-control study which sought to characterise the UK CRS population in terms of sociological, economic and medical factors. Using specific questions to examine participant responses relating to symptom exacerbation from food groups thought to be high in salicylate content, this analysis of the CRES database sought to compare an estimate of the prevalence of dietary sensitivity due to food with higher potential salicylate content across patients with CRS with (CRSwNPs) and without nasal polyposis (CRSsNPs) and with allergic fungal rhinosinusitis (AFRS).

Results: The CRSwNPs group were significantly more likely than controls to report symptom exacerbation due to ingestion of food groups with higher potential dietary salicylate content. The same trend was observed amongst CRSsNPs participants to a lesser degree. Reported response to the individual specific food groups wine, nuts, spicy foods, fruit and vegetables demonstrated that a statistically significant proportion of CRSwNPs and AFRS participants reported sensitivity to wine. 
Conclusions: This analysis suggests that there is an association between symptom exacerbation in response to food products with higher potential salicylate content, specifically wine, in CRS patients both with and without nasal polyposis when compared to controls, but especially in the CRSwNPs and AFRS phenotypes. Further studies are needed to detail if this relationship represents a causal relationship to dietary salicylate. The data present the possibility that a wider group of CRS patients may elicit salicylate sensitivity than those with known N-ERD.

Key words: rhinosinusitis, salicylate, asthma, aspirin exacerbated respiratory disease

\section{Introduction}

Salicylic acid is a phenolic phytohormone found in plants, with roles in growth and development, photosynthesis, transpiration, ion uptake and transport. Salicylic acid also induces specific changes in leaf anatomy and chloroplast structure, and is involved in endogenous signaling, thereby mediating plant defence against pathogens ${ }^{(1)}$. Salicylates are commonly found in a wide variety of foods, with unripe fruit and vegetables, spices, nuts and seeds thought to be particularly high in content. Assessments of daily consumption of salicylate vary, with a recent study in a Scottish population estimating daily intake to be $4.42 \mathrm{mg} /$ day for males and $3.16 \mathrm{mg} /$ day for females ${ }^{(2)}$. Formerly known as Samter's Triad and AERD, Non-Steroidal Exacerbated Respiratory Disease (N-ERD) is characterised by the coexistence of asthma, eosinophilic rhinosinusitis and nasal polyposis, with respiratory exacerbations triggered by ingestion of aspirin (acetylsalicylic acid) or other non-steroidal antiinflammatory medications (NSAIDs) ${ }^{(3,4)}$. N-ERD forms a subgroup of asthma and/or chronic rhinosinusitis (CRS) which is often refractory to commonly used medical and surgical therapies. $\mathrm{N}$ ERD is thought to affect $16 \%$ of patients with the subtype of CRS with nasal polyposis (CRSwNPs) ${ }^{(5)}$. A low-salicylate diet has been touted as a possible adjunct in the management of patients with N-ERD ${ }^{(6)}$. Whilst the impact of dietary salicylates in N-ERD is well recognised in the literature, little is known about the prevalence of dietary salicylate sensitivity across other phenotypes of CRS. The CRES dataset presented an opportunity to examine the prevalence of possible dietary salicylate sensitivity in all CRS patients regardless of their phenotype and any prior diagnosis of aspirin sensitivity.

\section{Objectives}

The Chronic Rhinosinusitis Epidemiology Study (CRES) was primarily designed to distinguish differences in socio-economic status, geography, medical/psychiatric co-morbidity, lifestyle and overall quality of life between patients with CRS and healthy controls, however patient-reported sensitivities to various foodstuffs were also captured as part of the study-specific questions. The specific aim of this analysis of the CRES database was to compare the prevalence of potential higher dietary salicylate sensitivity across CRS phenotypes (irrespective of prior diag- nosis of N-ERD) and compared to controls and characterise any differences between them. This will help to inform ENT surgeons and respiratory physicians of the potential role of avoidance of dietary salicylates in CRS patients' symptom control.

\section{Materials and methods}

The study was sponsored by the University of East Anglia (UEA) and funded by the Anthony Long and Bernice Bibby Trusts. Ethical approval was granted by the Oxford C Research Ethics Committee (Ref: 07/H0606/100).

\section{Study design}

The CRES was a prospective, questionnaire-based, case-control study conducted between October 2007 and September 2013 at 30 tertiary/secondary care sites across the United Kingdom. Patients with CRS and healthy control subjects were asked to complete a single, study-specific questionnaire, capturing a variety of demographic and socio-economic variables, environmental exposures and medical co-morbidities (Appendix 1).

\section{Participants and data sources}

Prospective participants were identified for recruitment at ENT outpatient clinics at 30 participating centres. Patients with CRS were examined by a clinician and classified by subgroup of CRS (CRSwNPs, CRSsNPs or AFRS) as per EPOS criteria (see below). Healthy controls were recruited from family members of patients attending ENT clinic, and from members of hospital staff at recruitment sites.

Questionnaires were completed during the clinic visit or taken home to be completed and returned by prepaid post. No participant identifiable data was captured therefore consent was not required by the ethics committee who stated that this was implied through return of the questionnaire. Returned questionnaires were scanned and the data imported into in an electronic database in Microsoft Excel. Records in the database were compared to physical copies of the questionnaires by two members of the research team to ensure accuracy and consistency between the two.

All CRS participants and healthy controls were required to meet the inclusion/exclusion outlined below: 


\section{CRS participants}

\section{Inclusion criteria}

Criteria for diagnosis of CRS with or without polyps (EPOS guidelines) ${ }^{(7)}$.

At least two symptoms must be present for at least 12 weeks and include:

- One of either nasal blockage/obstruction/congestion and/ or nasal discharge (anterior/posterior nasal drip)

- and either facial pain/pressure and/or reduction or loss of sense of smell

and additionally:

- endoscopic signs of: polyps and/or mucopurulent discharge primarily from middle meatus and/or; oedema/mucosal obstruction primarily in middle meatus

- and/or CT changes: mucosal changes within the ostiomeatal complex and/or sinuses.

Patients were then classified as having chronic rhinosinusitis without polyps (CRSsNPs), chronic rhinosinusitis with nasal polyps (CRSwNPs) or allergic fungal rhinosinusitis (AFRS); patients with the latter additionally adhered to either the Bent and Kuhn criteria $^{(8)}$ or the modified Vancouver criteria ${ }^{(9)}$.

\section{Healthy control participants}

\section{Exclusion criteria}

- Prior history of recurrent acute or chronic rhinosinusitis other than having had previous common colds (acute viral rhinosinusitis).

- Any other nose/sinus disorders e.g allergic rhinitis (hayfever).

- Active medical problems that have required a hospital visit within the last 12 months.

\section{Exclusion Criteria for Both Groups}

- Patients/controls unable to comprehend written English.

- Patients/controls under the age of 18 years.

\section{Quantitative variables and bias}

Dietary questions were added as an amendment to the original questionnaire in 2012 on recognition of the need to ask specific questions related to diet. Questions exploring potential dietary salicylate sensitivity asked "Have you ever experienced any allergy symptoms such as wheezing, runny nose, or itchy skin when taking any of the following?" with a simple Yes/No checkbox for the response. The question was intentionally phrased to focus on respiratory/nasal exacerbations characterised by itching, wheezing and rhinorrhoea, in order that those with common gastrointestinal intolerance would not answer "yes" for the purposes of this questionnaire. Food groups included in the questionnaire were chosen to cover a broad range of foods believed to have a high level of salicylate content (Table 1). Participants reporting a "yes" to any of the dietary questions were therefore

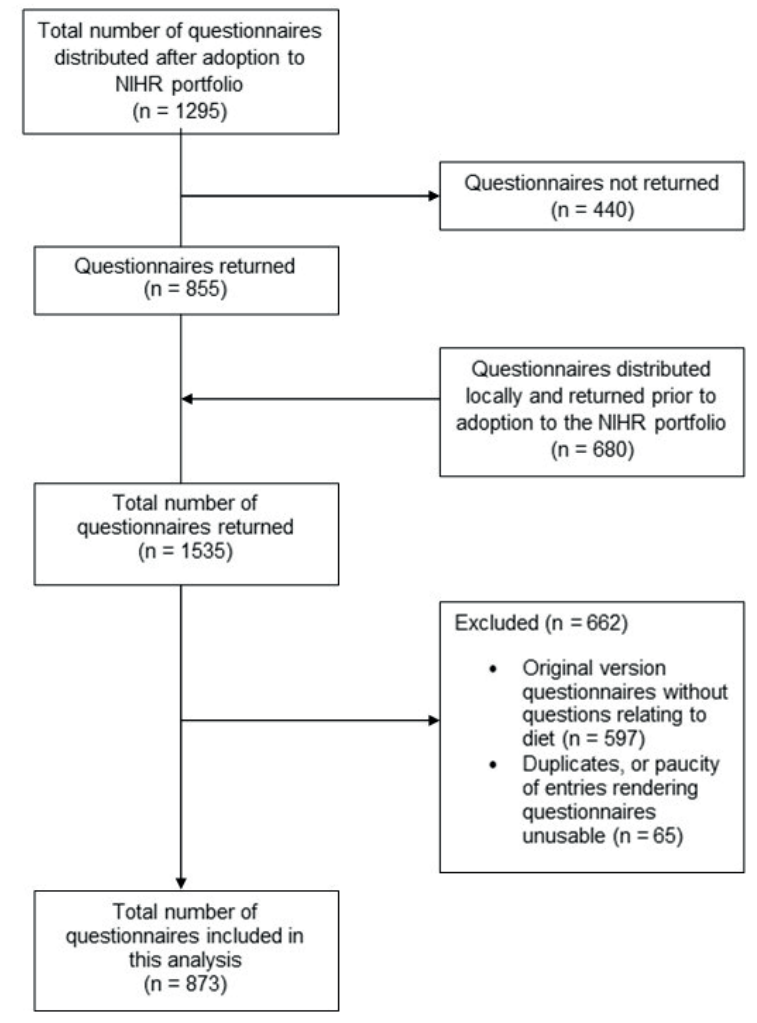

Figure 1. Participant flow diagram.

considered to have self-reported exacerbation of symptoms in response to foods of potential high salicylate content.

At the top of the list of food items, aspirin was also listed as an option to consider. For participants who also reported sensitivity to aspirin and also reported asthma as well as being diagnosed with CRSwNPs, were considered to have N-ERD for the purpose of this analysis; a more detailed analysis of asthma, N-ERD and inhalant allergy is reported elsewhere ${ }^{(10)}$.

\section{Sample size calculation}

Since this is a secondary analysis of an existing database, a power calculation was not performed for this specific analysis. The sample size calculation was based on the primary outcome of the study which was to look for common associations between socioeconomic factors and CRS. In order for the study to have $80 \%$ power to detect a difference of $10 \%$ in "low social class" between controls and CRS participants, assuming a 30\% rate in the CRS participants, with approximately 5 CRS participants to 1 control patient, 965 CRS participants and 193 controls were required ${ }^{(11)}$.

\section{Statistical methods}

All statistical analyses were conducted using IBM SPSS statistics v22. Proportions of CRS sub-groups reporting sensitivities to different food groups were compared by Chi-squared test or Fisher's exact test where appropriate. A Bonferroni correction was 
Table 1. Salicylate content of selected foods covered by questions included in the questionnaire.

\begin{tabular}{|c|c|c|c|c|c|c|c|}
\hline \multirow{3}{*}{ 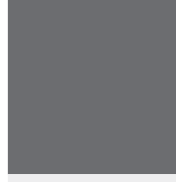 } & \multirow{3}{*}{ Food groups } & \multirow{3}{*}{$\begin{array}{c}\text { Malakar et al. } \\
2017\end{array}$} & \multicolumn{5}{|c|}{ Salicylic Acid Content (mg/100g) } \\
\hline & & & \multirow{2}{*}{$\begin{array}{l}\text { Swain et al. } \\
1985\end{array}$} & \multicolumn{4}{|c|}{ Frequency of sensitivity in CRES n (\%) } \\
\hline & & & & Control & CRSsNPs & CRSwNPs & AFRS \\
\hline \multirow[t]{8}{*}{ Spicy Foods } & & & & $19(17.3)$ & $72(21.4)$ & $85(21.1)$ & $4(16)$ \\
\hline & Chilli Powder & - & 1.3 & & & & \\
\hline & Curry Powder & - & 218 & & & & \\
\hline & Mustard Powder & - & 26 & & & & \\
\hline & Paprika & - & 203 & & & & \\
\hline & Red Chilli Peppers & 0.657 & 1.2 & & & & \\
\hline & Cumin Powder & 60.497 & 45 & & & & \\
\hline & Black Pepper & 4.57 & 6.2 & & & & \\
\hline \multirow[t]{4}{*}{ Wine* } & & & & $1(0.9)$ & $29(8.6)$ & $74(18.4)$ & $11(44.0)$ \\
\hline & White Wine & - & 0.1 & & & & \\
\hline & Red Wine & - & 0.9 & & & & \\
\hline & Champagne & - & 1.02 & & & & \\
\hline \multirow[t]{5}{*}{ Drinks* } & & & & $2(1.8)$ & $14(4.2)$ & $18(4.2)$ & $0(0.0)$ \\
\hline & Tea (English Breakfast) & 0.24 & 3 & & & & \\
\hline & Coffee (instant Caffeinated) & 0.204 & 0.59 & & & & \\
\hline & Drinking Chocolate & 5.148 & - & & & & \\
\hline & Coca-cola & - & 0.25 & & & & \\
\hline \multirow[t]{4}{*}{ Nuts } & & & & $0(0.0)$ & $12(3.6)$ & $17(4.2)$ & $4(16.0)$ \\
\hline & Almonds & 4.709 & 3 & & & & \\
\hline & Peanuts & - & 1.12 & & & & \\
\hline & Cashews & 4.11 & 0.07 & & & & \\
\hline \multirow[t]{8}{*}{ Fruit } & & & & $1(0.9)$ & $14(4.2)$ & $26(6.5)$ & $3(12.0)$ \\
\hline & Grapes (white) & 0.83 & - & & & & \\
\hline & Sultana & - & 1.88 & & & & \\
\hline & Dried dates & 3.69 & 4.5 & & & & \\
\hline & Nectarine & 1.328 & 0.49 & & & & \\
\hline & Peach & 0.33 & 0.58 & & & & \\
\hline & Apple (Granny Smith) & 0.97 & 0.59 & & & & \\
\hline & Raspberry & 1.052 & 3.14 & & & & \\
\hline \multirow[t]{7}{*}{ Vegetables } & & & & $0(0.0)$ & $3(0.9)$ & $2(0.5)$ & $2(8.0)$ \\
\hline & Broccoli & 1.101 & 0.65 & & & & \\
\hline & Green Beans & 1.388 & 0.11 & & & & \\
\hline & Garden Peas & 2.552 & 0.004 & & & & \\
\hline & Tinned Tomato & 0.642 & 0.53 & & & & \\
\hline & Spinach & 0.229 & 0.58 & & & & \\
\hline & Sweet Potato & 2.115 & 0.48 & & & & \\
\hline
\end{tabular}

*Values reported as $\mathrm{mg} / 100 \mathrm{ml}$.

applied to correct for multiple testing (0.05/6) (6 main groups of foods), resulting in $\mathrm{p}<0.008$ being considered statistically significant. Odds ratios were calculated for main food groups and individual food groups by binary logistic regression and adjusted for potential confounding variables. For the purposes of regression, the AFRS group was merged with the CRSwNPs group due to the small sample size of the former.

\section{Results}

Study Participants 


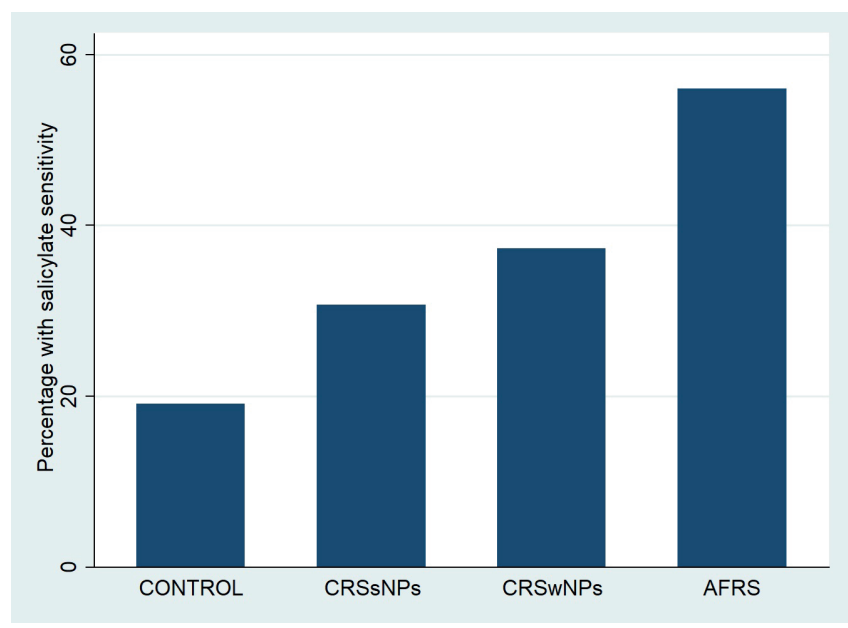

Figure 2. Proportion of participants in each group reporting asthma and aspirin sensitivity, and sensitivity to one or more salicylate containing food groups. CRSwNPs = Chronic Rhinosinusitis with nasal polyps; CRSsNPs = Chronic Rhinosinusitis without nasal polyps; AFRS = Allergic Fungal Rhinosinusitis.

A total of 1535 questionnaires were returned with 1470 considered eligible for inclusion after removal of duplicates and questionnaires with missing data (Figure 1). However, questions relating to diet and allergy were added part way through the recruitment period. This analysis is therefore based on the 873 participants who completed the updated version of the questionnaire that included the dietary questions. The overall response rate of those identified to take part in the study was $66 \%$ of those distributed for the entire study.

\section{Descriptive data}

Of the 873 participants, 402 (46.0\%) were CRSwNPs, 336 (38.5\%) CRSsNPs, 25 (2.9\%) AFRS and 110 (12.6\%) controls. The demographic characteristics of each group are demonstrated in Table 2. Controls were generally younger than CRS participants and had a greater proportion of females. Cases and controls were broadly similar in having a majority proportion of White British participants. The CRSwNPs and AFRS groups had a greater proportion of participants with asthma $(52.5 \%$ and $68.0 \%$ respectively) and sensitivity to aspirin (10.4\% and 44.0\%). 9.9\% (40 participants) of the CRSwNPs group and $40 \%$ (10 participants) of the AFRS group reported both asthma and sensitivity to aspirin as defined above. Amongst this subset of participants with concurrent asthma and aspirin sensitivity, a comparable proportion of the CRSwNPs group and AFRS group also reported sensitivity to one or more of the food groups $(65.0 \%$ and $60 \%$, respectively; Figure 2).

\section{Primary outcome data and main results}

Participants with nasal polyps (including both those with CRSwNPs and AFRS) were most likely to report symptom exacerbation to one or more of the food groups included in the questionnaire when compared with controls. However, a breakdown of the analysis to specific food groups determined that of all possible paired combinations of controls, CRSwNPs and AFRS showed statistically significant variation in the proportion of participants reporting sensitivity to wine (Controls 0.9\%, CRSwNPs 18.4\%, AFRS 44.0\%, p<0.001), as demonstrated in Figure 3. Participants with AFRS also reported significantly more reactions to nuts than controls ( $16.0 \%$ vs $0 \%, p=0.001)$.

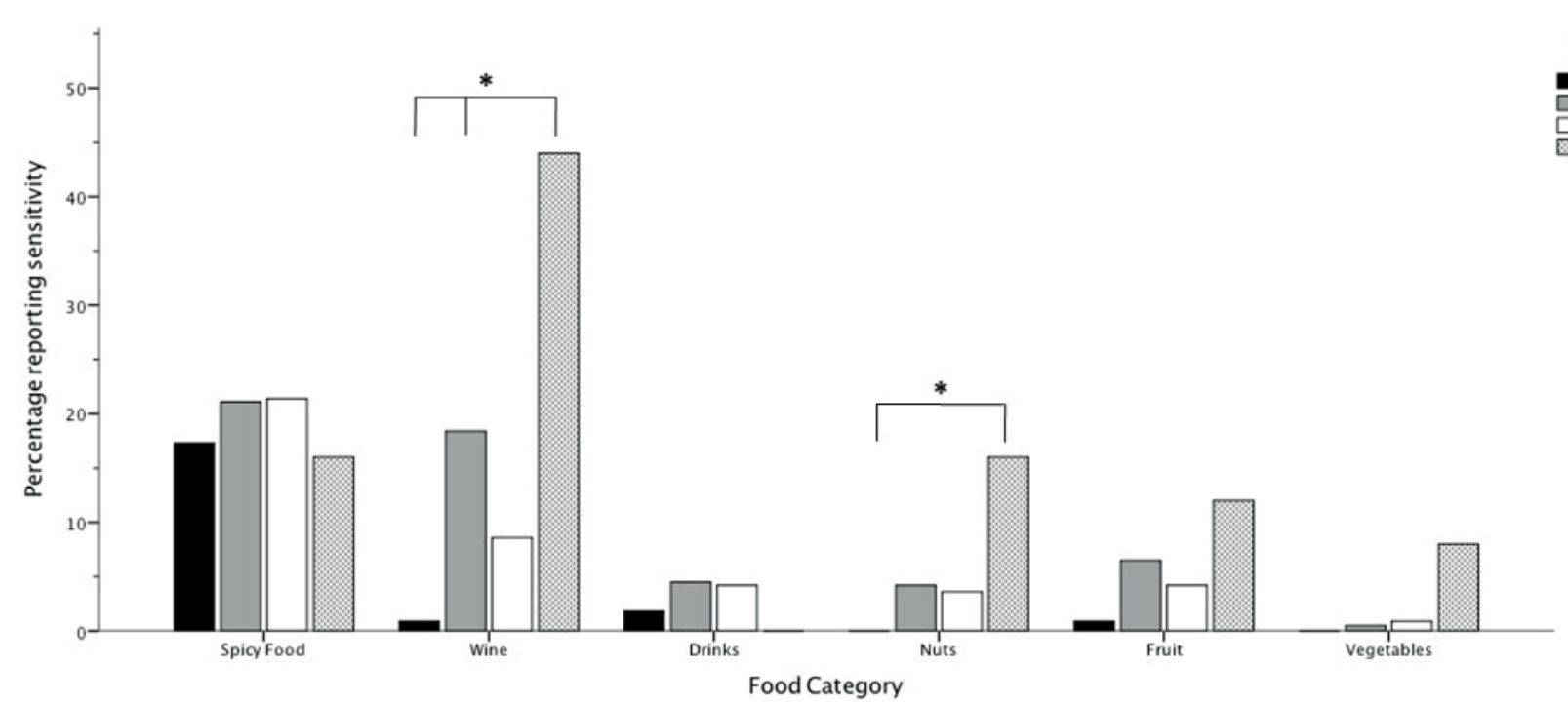

Figure 3. Proportion of control group and CRS subgroups reporting sensitivity/symptom exacerbation. *Pairs statistically significant at $\mathrm{p}<0.008$ (Bonferroni correction). CRSwNPs = Chronic Rhinosinusitis with nasal polyps; CRSsNPs = Chronic Rhinosinusitis without nasal polyps; AFRS = Allergic Fungal Rhinosinusitis. 
Table 2. Demographics and selected health characteristics of study population.

\begin{tabular}{|c|c|c|c|c|}
\hline Characteristic & $\begin{array}{l}\text { Controls } \\
(n=110)\end{array}$ & $\begin{array}{l}\text { CRSwNPs } \\
(n=402)\end{array}$ & $\begin{array}{l}\text { CRSsNPs } \\
(n=336)\end{array}$ & $\begin{array}{c}\text { AFRS } \\
(n=25)\end{array}$ \\
\hline $\begin{array}{l}\text { Age (years) (SD } \\
\text { in brackets) }\end{array}$ & $44( \pm 14.9)$ & $55( \pm 14.9)$ & $51( \pm 15.5)$ & $57( \pm 14.1)$ \\
\hline Female n (\%) & $71(64.5)$ & 119 (29.6) & $159(47.3)$ & $15(60.0)$ \\
\hline $\begin{array}{l}\text { White British } \\
\mathrm{n}(\%)\end{array}$ & 95 (86.4) & 297 (73.9) & $235(69.9)$ & $22(88.0)$ \\
\hline Asthma n (\%) & $5(4.5)$ & $211(52.5)$ & $73(21.7)$ & $17(68.0)$ \\
\hline $\begin{array}{l}\text { Aspirin } \\
\text { Sensitivity n (\%) }\end{array}$ & $1(0.9)$ & $42(10.4)$ & $10(3.0)$ & $11(44.0)$ \\
\hline Both above $\mathrm{n}(\%)$ & $0(0)$ & $40(9.9)$ & $4(1.2)$ & $10(40)$ \\
\hline
\end{tabular}

Missing data excluded.

Although several other pairs were found to be significant at the $\mathrm{p}<0.05$ level (Fruit; Controls vs CRSwNPs $\mathrm{p}=0.04$, Controls vs AFRS $p=0.02$, Vegetables; Controls vs AFRS $p=0.03, C R S w N P s$ vs AFRS $p=0.01, C R S s N P s$ vs AFRS $p=0.04$ ), these associations were not found to be statistically significant after the Bonferroni correction was applied.

After adjusting for potential confounders including age, sex, and aspirin sensitivity, the association between foods with higher potential dietary salicylate and symptom exacerbation was enhanced (adjusted OR 3.16, 95\% Cl $1.78-5.61$, p<0.001), as demonstrated in Table 3; the adjustment accounted for differences in the subgroup demographics ${ }^{(11)}$. The CRSsNPs group were also found to be more likely to report sensitivity than controls (adjusted OR 2.03, 95\% Cl 1.15 - 3.58, p=0.01), although to a lesser degree than the group with nasal polyposis. Separately, $56 \%(n=14)$ of the AFRS group reported symptom exacerbation, although this group was not included individually in the regression analysis due to the small sample size of 25 participants. A further analysis to remove participants who reported autoimmune disorders, ciliary dyskinesias and immunodeficiencies, did not change the associations reported above (Table 3a).

\section{Discussion}

The Chronic Rhinosinusitis Epidemiology Study is the largest epidemiological study of CRS in the UK to date and is believed to be the first study to collect data on patient reported symptom exacerbation in response to ingestion of foods with higher potential salicylate content in CRS subtypes other than the N-ERD subgroup. Other studies investigating sensitivity to foodstuffs in CRS subgroups have focused on non-specific food sensitisation and delayed food hypersensitivity measured by skin prick testing ${ }^{(12,13)}$.

\section{Key results}

Within the CRES population we observed a significantly increased risk of reported symptom exacerbation to wine in CRS participants both with and without nasal polyps when compared to controls. The CRSwNPs group were 3 times more likely than controls to report these responses. This likely reflects the inclusion of AFRS subjects in the test group and the fact that almost $10 \%$ of the CRSwNPs group fulfilled the criteria for $\mathrm{N}$ -

Table 3. Association between CRS subtype and dietary salicylate sensitivity. The results demonstrate the association in participants who reported sensitivity to one or more of the sub groups of foods.

\begin{tabular}{|c|c|c|c|c|c|c|c|c|}
\hline Group & Total (n) & $\begin{array}{l}\text { Dietary Salicylate } \\
\text { Sensitivity (\%) }\end{array}$ & Crude OR & $95 \% \mathrm{Cl}$ & p value & Adjusted OR* & $95 \% \mathrm{Cl}$ & p value \\
\hline Controls & 110 & $21(19.1)$ & 1.00 & & & 1.00 & & \\
\hline CRSwNPs & 402 & $150(37.3)$ & 2.52 & $1.50-4.23$ & $<0.001$ & 2.56 & $1.39-4.71$ & 0.002 \\
\hline CRSsNPs & 336 & $103(30.7)$ & 1.87 & $1.10-3.18$ & 0.020 & 1.86 & $1.05-3.30$ & 0.034 \\
\hline AFRS & 25 & $14(56.0)$ & 5.39 & $2.15-13.56$ & $<0.001$ & 3.84 & $1.36-10.86$ & 0.011 \\
\hline
\end{tabular}

*Odds ratio adjusted for age, sex, asthma and aspirin sensitivity.

Table 3a. Association between CRS subtype and dietary salicylate sensitivity. The results demonstrate the association in participants who reported sensitivity to one or more of the sub groups of foods excluding individuals who reported yes to having an autoimmune disorder, immunodeficiency or ciliary dysmotility.

\begin{tabular}{|c|c|c|c|c|c|c|c|c|}
\hline Group & Total (n) & $\begin{array}{l}\text { Dietary Salicylate } \\
\text { Sensitivity (\%) }\end{array}$ & Crude OR & $95 \% \mathrm{Cl}$ & p value & Adjusted OR* & $95 \% \mathrm{Cl}$ & p value \\
\hline Controls & 109 & $21(19.3)$ & 1 & & & 1 & & \\
\hline CRSwNPs & 379 & $139(36.7)$ & 1.70 & $0.99-2.90$ & 0.054 & 1.78 & $1.00-3.19$ & 0.051 \\
\hline CRSsNPs & 302 & $87(28.8)$ & 2.43 & $1.44-4.08$ & 0.001 & 2.59 & $1.40-4.80$ & 0.003 \\
\hline AFRS & 23 & $14(60.9)$ & 6.52 & $2.49-17.08$ & $<0.001$ & 4.90 & $1.64-14.63$ & 0.004 \\
\hline
\end{tabular}


ERD. The proportion of CRSwNPs participants suspected to have $\mathrm{N}$-ERD in our study is lower than the $16 \%$ observed by Stevens et al. in a US population and may be a result of methodological differences between the studies ${ }^{(5)}$.

The fact that the prevalence of reported symptom exacerbation to food products containing potentially higher levels of salicylate is higher than patient reported aspirin sensitivity amongst CRS participants in our study could suggest that some participants may also be sensitive to aspirin but are unaware, although this relationship could be confounded by respiratory sensitivity to other dietary components which commonly cause respiratory symptoms such as sulphites ${ }^{(14)}$, which is true of wine where the biggest effect was seen. Potential symptoms arising from sulphite ingestion includes dermatitis, urticaria, flushing, hypotension, abdominal pain, diarrhoea, exacerbation of asthma and anaphylaxis. Sulphite sensitivity is reported to be prevalent in 3 to $10 \%$ of asthmatic subjects who ingest them ${ }^{(14)}$.

In the CRES qualitative sub-study, Erskine et al. determined that dietary factors were frequently perceived to be a trigger for respiratory exacerbations, with wine being a specific trigger highlighted by one participant ${ }^{(15)}$. Esmaeilzadeh et al. used an oral food challenge test in patients with CRSwNPs and found $69.9 \%$ of patients to be salicylate sensitive ${ }^{(16)}$. Interestingly, they reported red grape to be one of the most common foods inducing a reaction. Our finding that CRS participants frequently reported sensitivity to wine also suggests that grapes are a common trigger of sensitivity, but it is very possible that in some participants this may be an effect of alcohol and/or sulphites as discussed above. There is recent evidence to show the effect of alcohol on symptom exacerbation in CRSwNPs was significantly more prevalent in patients suffering from recurrent disease and in patients with severe symptomatology (17).

Unlike aspirin sensitivity in the setting of N-ERD which is the result of abnormal arachidonic acid metabolism causing inhibition of cyclooxygenase-1 (COX-1) and a subsequent imbalance of inflammatory mediators ${ }^{(18)}$, non-acetylated salicylates of dietary origin have been shown to selectively inhibit cyclooxygenase-2 (COX-2) gene expression ${ }^{(19)}$. COX-2 is known to be down-regulated in the nasal polyps of patients with N-ERD ${ }^{(20-22)}$. It is therefore hypothesised that in addition to reactions to aspirin and other NSAIDs, patients with N-ERD are also likely to experience sensitivity to dietary sources of salicylates. Interestingly the CRSsNPs group in our study also demonstrated an increased risk of dietary salicylate sensitivity compared to controls. This likely points to the fact that current classification/phenotypic divisions of CRS do not necessarily reflect pathophysiological subgroups for which true endotypes are yet to be fully determined. Our data also appears to highlight an overlap between N-ERD and AFRS aetiopathogenic factors, as over half of AFRS participants appear to report symptom exacerbation. Whilst the small size of the AFRS group included in this study renders it difficult to draw definitive conclusions, the fact that similar proportions of participants in the AFRS and CRSwNPs groups with concurrent asthma and aspirin sensitivity (thereby suggestive of $\mathrm{N}$-ERD) also report symptom exacerbation to dietary salicylates, suggests there may be some commonality between the two groups. We suggest that N-ERD should be considered in all CRS patients who report symptom exacerbation in response to ingestion of food products with higher potential dietary salicylate content, the implications being identification of a more severe disease endotype, with early involvement of respiratory physicians where appropriate. If indeed there is overlap between the pathophysiological disease mechanisms of N-ERD and AFRS, aspirin desensitisation may be a potentially therapeutic option for the latter; but at the very least, patients can be advised to avoid wine and possibly nuts in order to prevent symptom exacerbations.

\section{Interpretation}

The interaction between diet and CRS is complex and poorly understood. A number of special diets including a low salicylate diet have a theoretical basis for being able to modulate the chronic inflammation seen in CRS, but the evidence for the clinical application of dietary adjustment in management is lacking and is not recommended in national guidelines ${ }^{(23)}$. In a small randomized control crossover trial of $10 \mathrm{~N}-\mathrm{ERD}$ patients, Sommer et al. investigated the use of the low salicylate diet as a management option in N-ERD and observed an improvement in both subjective and objective outcome measures in patients following the diet for a 6-week period ${ }^{(6)}$. The feasibility of implementing such a strategy as a treatment adjunct was questioned in a recent update on the management of N-ERD which highlighted the problem of long term adherence to the diet given the large number of commonly eaten foods containing salicylates ${ }^{(24)}$.

\section{Limitations}

Our results should be interpreted in the context of the limitations of the questionnaire-based design of the study. Whilst positive responses to questions regarding reactions to foods thought to be high in dietary salicylates are suggestive of potential symptom exacerbation, only objective allergy testing or provocation tests could conclusively determine if this is the case ${ }^{(25)}$ and itchy skin in isolation is not a CRS symptom; some asthmatics also avoid NSAIDs on advice from their GP and need a provocation test for confirmation. The self-reported nature of the respiratory sensitivity also renders the subject to recall bias, however, other studies have used a similar means of capturing data ${ }^{(17)}$. Despite this, the potential error in recall should be equal across CRS subgroups and controls and therefore should not overly bias the results in any one subgroup. Furthermore, this study focused on a limited number of broad food groups 
thought to represent foods of moderate to high salicylate content. Future studies using validated food diaries and objective allergy testing are warranted to further investigate the potential role of dietary salicylate in CRS symptom exacerbation.

Another limitation is the over-reporting of food sensitivities by the general population. About $1-2 \%$ of the population have a medically diagnosed food allergy/sensitivity and yet $13 \%$ claim to have one ${ }^{(26)}$. In our controls, $19 \%$ said they had a sensitivity, therefore it is possible that the real level of food sensitivity in our groups will probably be much lower than what they self-report. Table 1 also demonstrates the variability in the reported levels of salicylate in food, making categorisation of "high salicylate" foods somewhat problematic.

\section{Generalisability}

Studies of the potential role of dietary salicylates in CRS, such as our study and that carried out by Sommer et al, are hindered by the lack of consensus on the salicylate content of foodstuffs as demonstrated in Table 1. The inconsistency in the literature is thought to be the result of methodological variation, along with differences in the variety, growing conditions and preparation of foods analysed ${ }^{(27)}$. Further basic science studies are required in order for accurate diet-based studies into the role of dietary salicylates in clinical conditions such as CRS to be carried out in the future.

\section{Conclusion}

This analysis suggests that there is an association between symptom exacerbation in response to food products with higher potential salicylate content, specifically wine, in CRS patients both with and without nasal polyposis when compared to controls, but especially in the CRSwNPs and AFRS phenotypes.
Further studies are needed to detail the relationship between dietary intake and CRS subgroups and to determine if this apparent airway sensitivity is specifically a salicylate effect and moreover as to the reality of meaningful dietary modifications. The data present the possibility that a wider group of CRS patients may elicit salicylate sensitivity than those with known N-ERD.

\section{Acknowledgements}

NIHR portfolio ID: 12926; The study was funded by the Anthony Long Trust (postage costs) and the Bernice Bibby Trust (research nurse time).

\section{Authorship contribution}

According to the ICMJE authorship criteria:

1. substantial contributions to conception and design of, or acquisition of data or analysis and interpretation of data

2. drafting the article or revising it critically for important intellectual content

3. final approval of the version to be published

1, 2 and 3: CP, RS, SE, CH, SC, JR, NK, AR, SA, NK, VS, RA

2 and $3: \mathrm{RS}, \mathrm{CD}-\mathrm{H}, \mathrm{AW}$.

\section{Conflict of interest}

No conflict of interest.

\section{Ethical approval and consent to participate}

The CRES was approved by the Oxford C Research Ethics Committee (Ref: 07/H0606/100), sponsored by the University of East Anglia (UEA).

This study has been reported in accordance with the STROBE statement guidelines for the reporting of observational studies.

\section{References}

1. Robert-Seilaniantz A, Navarro L, Bari R and Jones JD. Pathological hormone imbalances. Curr Opin Plant Biol. 2007; 10: 372-9.

2. Wood A, Baxter G, Thies F, Kyle J and Duthie G. A systematic review of salicylates in foods: estimated daily intake of a Scottish population. Mol Nutr Food Res. 2011; 55 Suppl 1: S7-S14.

3. Szczeklik A and Stevenson DD. Aspirininduced asthma: advances in pathogenesis, diagnosis, and management. The Journal of allergy and clinical immunology. 2003; 111 : 913-21; quiz 22.

4. Samter M and Beers RF, Jr. Intolerance to aspirin. Clinical studies and consideration of its pathogenesis. Ann Intern Med. 1968, 68: $975-83$.

5. Stevens WW, Peters AT, Hirsch AG, et al. Clinical Characteristics of Patients with Chronic Rhinosinusitis with Nasal Polyps, Asthma, and Aspirin-Exacerbated
Respiratory Disease. J Allergy Clin Immuno Pract. 2017; 5: 1061-70 e3.

6. Sommer DD, Rotenberg BW, Sowerby $L J$ et al. A novel treatment adjunct for aspirin exacerbated respiratory disease: the lowsalicylate diet: a multicenter randomized control crossover trial. Int Forum Allergy Rhinol. 2016; 6: 385-91.

7. Fokkens WJ, Lund VJ, Mullol J, et al. European Position Paper on Rhinosinusitis and Nasal Polyps 2012. Rhinol Suppl. 2012 23: 3 p preceding table of contents, 1-298.

8. Bent JP, 3rd and Kuhn FA. Diagnosis of allergic fungal sinusitis. Otolaryngol Head Neck Surg. 1994; 111: 580-8.

9. Philpott CM, Javer AR and Clark A. Allergic fungal rhinosinusitis - a new staging system. Rhinology. 2011; 49: 318-23.

10. Philpott CM, Erskine S, Hopkins C, et al Prevalence of asthma, aspirin sensitivity and allergy in chronic rhinosinusitis: data from the UK National Chronic Rhinosinusitis
Epidemiology Study. Respir Res. 2018; 19 : 129

11. Philpott C, Erskine S, Hopkins C, et al. A case-control study of medical, psychological and socio-economic factors influencing the severity of chronic rhinosinusitis. Rhinology. 2016; 54: 134-40.

12. Pang YT, Eskici $O$ and Wilson JA. Nasal polyposis: role of subclinical delayed food hypersensitivity. Otolaryngol Head Neck Surg. 2000; 122: 298-301.

13. Al-Qudah M. Food Sensitization in Medically Resistant Chronic Rhinosinusitis with or without Nasal Polyposis. Int Arch Allergy Immunol. 2016; 169: 40-4.

14. Vally $\mathrm{H}$ and Misso NL. Adverse reactions to the sulphite additives. Gastroenterol Hepatol Bed Bench. 2012; 5: 16-23.

15. Erskine SE, Notley C, Wilson AM and Philpott CM. Managing chronic rhinosinusitis and respiratory disease: a qualitative study of triggers and interactions. J Asthma. 2015; 
52: 600-5

16. Esmaeilzedeh H, Esmaeilzadeh E, Faramarzi M, Nabavi M and Farhadi M. Salicylate Food Intolerance and Aspirin Hypersensitivity in Nasal Polyposis. Iran J Immunol. 2017; 14 81-8.

17. De Schryver E, Derycke L, Campo P, et al. Alcohol hyper-responsiveness in chronic rhinosinusitis with nasal polyps. Clin Exp Allergy. 2017; 47: 245-53.

18. Kennedy JL, Stoner AN and Borish L. Aspirin-exacerbated respiratory disease: Prevalence, diagnosis, treatment, and considerations for the future. Am J Rhinol Allergy. 2016; 30: 407-13.

19. Hare LG, Woodside JV and Young IS. Dietary salicylates. J Clin Pathol. 2003; 56: 649-50.

20. Picado C, Fernandez-Morata JC, Juan M, et al. Cyclooxygenase-2 mRNA is downexpressed in nasal polyps from aspirin-sensitive asthmatics. Am J Respir Crit Care Med. 1999; 160: 291-6.

21. Mullol J, Fernandez-Morata JC, Roca-Ferrer
J, et al. Cyclooxygenase 1 and cyclooxygenase 2 expression is abnormally regulated in human nasal polyps. J Allergy Clin Immunol. 2002; 109: 824-30.

22. Roca-Ferrer J, Garcia-Garcia FJ, Pereda J, et al. Reduced expression of COXs and production of prostaglandin $E(2)$ in patients with nasal polyps with or without aspirinintolerant asthma. J Allergy Clin Immunol. 2011; 128: 66-72 e1

23. Nayan S, Maby A, Endam LM and Desrosiers M. Dietary modifications for refractory chronic rhinosinusitis? Manipulating diet for the modulation of inflammation. Am J Rhinol Allergy. 2015; 29: e170-4.

24. Woessner KM. Update on AspirinExacerbated Respiratory Disease. Curr Allergy Asthma Rep. 2017; 17: 2.

25. Kowalski ML, Agache I, Bavbek S, et al. Diagnosis and management of NSAIDExacerbated Respiratory Disease (N-ERD)-a EAACI position paper. Allergy. 2019; 74: 28-39.
26. Verrill L, Bruns R and Luccioli S. Prevalence of self reported food allergy in US adults: 2001, 2006, and 2010. Allergy Asthma Proc. 2015.

27. Malakar S, Gibson PR, Barrett JS and Muir JG. Naturally occurring dietary salicylates: A closer look at common Australian foods. J Food Compos Anal. 2017; 57: 31-9.

Prof. Carl M. Philpott Norwich Medical School University of East Anglia Norfolk NR4 7TJ

United Kingdom

E-mail:C.Philpott@uea.ac.uk

Appendix 1. Study questionnaire.

-

Ref: $\square \square \square$

Please try to fill in ALL parts of the questionnaire, even if you do not have sinus problems and do not feel they are directly relevant to you.

\section{T+ University of East Anglia}

\section{CHRONIC RHINOSINUSITIS EPIDEMIOLOGY STUDY (CRES)}

\begin{tabular}{llll|}
\hline FOR DOCTOR TO COMPLETE: & & & \\
CRS WITHOUT POLYPS & $\square$ & CONFIRMATION OF DIAGNOSIS WITH: \\
CRS WITH POLYPS & $\square$ & CT SCAN $\square$ & ENDOSCOPY $\square$ \\
CONFIRMED/SUSPECTED AFRS & $\square$ & & \\
CONTROL & $\square$ & & \\
\hline
\end{tabular}

\begin{tabular}{|lllll|}
\hline RECRUITMENT SITE & & & \\
JPUH $\square$ & NNUH $\square$ & WWL $\square$ & SPIRE $\square$ & NGH $\square$ \\
LDH $\square$ & RSCH $\square$ & GUYS $\square$ & QMC $\square$ & FH $\square$ \\
Cl $\square$ & SRI $\square$ & SGH $\square$ & BCUH $\square$ & RAH $\square$ \\
IRH $\square$ & HEFT $\square$ & QEH $\square$ & STH $\square$ & WI $\square$ \\
OUH $\square$ & SAMBU $\square$ & CTHB $\square$ & WHH $\square$ & PHNT $\square$ \\
RCH $\square$ & RGH $\square$ & AUHNT $\square$ & RBNFT $\square$ & HWPH $\square$ \\
DBH $\square$ & Other $\square$ Other, please specify: & & \\
& & & \\
\end{tabular}

Please return the questionnaire to the Norwich Medical School, UEA, Norwich -for the attention of Mr Carl Philpott

$\square$

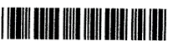

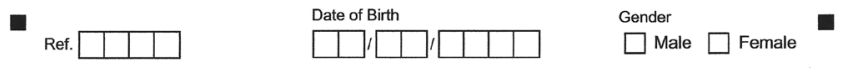

How to fill this form in

This form will be 'read' by a computer and therefore it is important to take care when completing it. Where you are asked to enter text or numbers, please print in CAPITAL letters with one letter/number per box.

Where vou are asked to indicate your choice. fill in the aporopriate box thus:

What is your occupation? Please enter your occupation below (One letter per box)

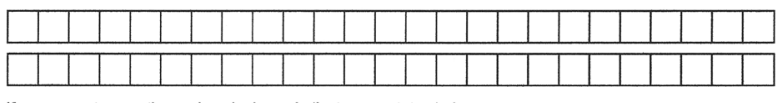

If you are not currently employed, please indicate your status below

$\square$ Retired If retired, please state your occupation previously as well
$\square$ Unemployed If unemployed, please state your partner's occupation (if married/co-habiting)
$\square$ Student If student living with parents, please state the occupation of your parents (both)
What is your highest academic qualification? $\quad \square$ GCSE $\square$ A-Level $\square$ NVQ $\square$ Degree $\square$ Higher Degree

Do you live in a village or a town/city or on the outskirts of a town/city? $\square$ village $\square$ suburbs $\square$ urban

How long have you lived there for? $\square$ < year $\quad \square$ 1-3 yrs $\quad \square$ 3-5 yrs $\square>5$ yrs

Do you live near any crop field e.g oil seed rape? $\square$ Yes $\square$ No If yes please state

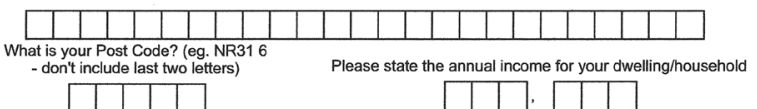

\begin{tabular}{|l|l|l|l|l|l|l|l}
\hline & 1 & & & & \\
\hline
\end{tabular}

Do you have any specific dietary modifications? $\quad \square$ Yes $\square$ No If yes please state

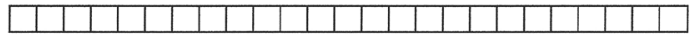

How many people live in your house/dwelling including yourself? $\quad \square^{1} \quad \square^{2} \quad \square^{3} \quad \square^{4} \quad \square>4$ How much do you smoke per day (cigarettes/cigars etc.)? $\square$ None $\square$ 1-10 $\square$ 11-20 $\square>20$ How many units of alcohol do you drink each week? $\quad \square$ None $\quad \square$ 1-10 $\quad \square^{11-30} \quad \square$-30
(1 unit = 1/2 pint of beer or 1 glass of wine)

Have you seen your GP for anxiety? $\square$ Yes $\square$ No

Have you seen your GP for depression? $\quad \square$ Yes $\square$ No

Besides anxiety and depression, do you have any other psychiatric illness? $\square$ Yes $\square$ No If yes please state 
(1)

Ref. \begin{tabular}{l|l|l|}
\hline & & \\
\hline
\end{tabular}

Do you have any of the following?

Ciliary dysmotility (e.g Cystic Fibrosis, Kartangener's syndrome, Primary Ciliary Dyskinesia) (disorder where the little hairs on the cells lining the air passages don't work properly)?

Hypothyroidism (underactive thyroid gland)?

Autoimmune disorder (e.g.systemic lupus erythmatosis, rheumatoid arthritis)?

Yes No

$\square \square$

$\square \quad \square$

$\square \square$

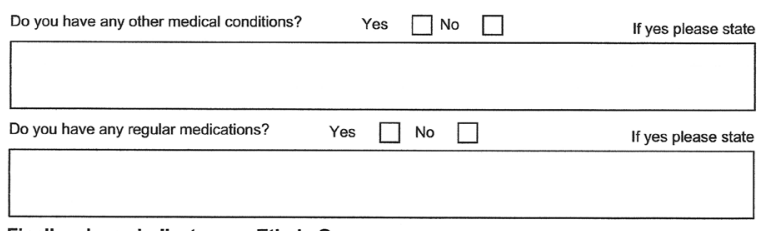

Finally, please indicate your Ethnic Group

\section{$\square \quad$ WHITE - British}

$\square$ WHITE - Irish

$\square \quad$ WHITE - Other White background

$\square \quad$ MIXED - White \& Black Caribbean

$\square \quad$ MIXED - Other Mixed background*

$\square \quad$ ASIAN or ASIAN BRITISH - Indian

$\square \quad$ ASIAN or ASIAN BRITISH - Pakistani

$\square$ ASIAN or ASIAN BRITISH - Bangladeshi

$\square$ ASIAN or ASIAN BRITISH - Other Asian background *

$\square$ BLACK or BLACK BRITISH - Caribbea

BLACK or BLACK BRITISH - African

$\square$ BLACK or BLACK BRITISH - Other Black background *

$\square \quad$ OTHER - Chinese

$\square$ OTHER - Any other group *

* Please state details or country of origin

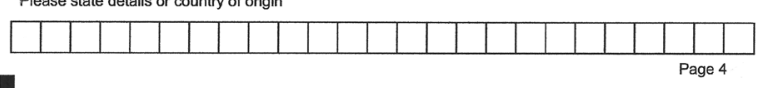

|||||||||||||||||||||||||||||
Ref. $\square \square \square$

Do you have any of the following?

Yes No

Ciliary dysmotility (e.g Cystic Fibrosis, Kartangener's syndrome, Primary Ciliary Dyskinesia)
(disorder where the little hairs on the cells lining the air passages don't work properly)?

Hypothyroidism (underactive thyroid gland)?

Autoimmune disorder (e.g.systemic lupus erythmatosis, rheumatoid arthritis)?

$\square \quad \square$

$\square \quad \square$

Do you have any other medical conditions? $\quad$ Yes $\square$ No $\square$

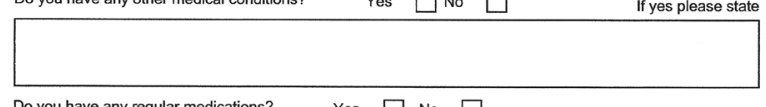

Do you have any regular medications? $\quad$ Yes $\square$ No $\square \quad$ If yes please state

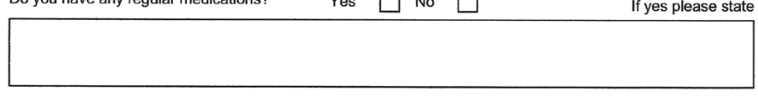

Finally, please indicate your Ethnic Group

$\square$ WHITE - British

$\square$ WHITE - Irish

$\square$ WHITE - Other White background

$\square \quad$ MIXED - White \& Black Caribbean

$\square$ MIXED - White \& Black African

MIXED - White \& Asian

$\square \quad$ MIXED - Other Mixed background*

$\square \quad$ ASIAN Or ASIAN BRITISH - Indian

$\square$ ASIAN or ASIAN BRITISH - Pakistan

$\square$ ASIAN or ASIAN BRITISH - Bangladesh

$\square \quad$ ASIAN or ASIAN BRITISH - Other Asian background *

$\square$ BLACK or BLACK BRITISH - Caribbean

BLACK or BLACK BRITISH - African

$\square$ BLACK or BLACK BRITISH - Other Black background *

$\square \quad$ OTHER - Chinese

$\square$ OTHER - Any other group *

"Please state details or country of origin

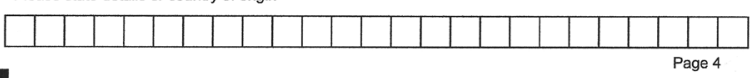

